\title{
THE VALUE OF PARTICULAR SPORTS OF THE WHEELCHAIR- DISABLED IN MAINTAINING HEALTH OF THE PARAPLEGIC
}

By Prof. Kurt-Alphons Jochheim and Horst Strohkende, Dipl. Sportl. Seminar für Rehabilitation an der Deutschen Sporthochschule, Köln, West Germany

THE different types of sports of the wheelchair-disabled are referred to and applied more intensely under the aspect of their psychological effects in the realm of clinical rehabilitation (Heipertz, 1956, 1964). The incentive of physical exercises toward activity promises, especially for the younger disabled, a stabilisation of the personality and social integrative effects by enabling experiences of success and mutual participation. The general increase of the level of activity makes the achievement of these rehabilitative goals in professional and social life more probable. The muscular and coordinative improvements, which can be achieved through physical exercises, are pushed more or less into the background in the clinic since other physiotherapeutic measures are generally accepted. It is hardly surprising that the question of the value of sports in the light of physical fitness and the stabilisation of the health, has found little consideration.

When the paraplegic is discharged from hospital, the value of particular sports activities enters little into the interest of rehabilitation. Everyone aquainted with these conditions is well aware how difficult it is to retain once-achieved physical fitness in daily life. The physiotherapeutic care suddenly ceases and the daily initiative is left to the disabled. As own initiative with the demands of the job, there is often lack of willpower to continue. To carry on sport solely as practised in hospital cannot suffice the demands. The value of a rehabilitative technique must be seen first under the aspect of the daily requirement and risk to the paraplegic. The question, 'to what extent can the practising of a certain sport be of a rehabilitative contribution', should be answered with the help of criteria from the field of sports medicine. Questions of organisation and effectiveness are certainly important, if services for the physical well-being of the disabled are considered.

II. The Daily Demand and Risk for the Paraplegic. The paraplegic is employed primarily in jobs requiring little physical exertion and can be usually carried out in one place. The work demands predominantly concentration and endurance of the person with consecutive fatigue. The common duties are rather time consuming but physically not challenging. Periods of bodywork load are just covering short intervals (e.g. lifting and support of the body; in the wheelchair, in the car, in the bathroom, etc.).

The eating habits as well as the use of such luxuries as tobacco and alcohol appear frequently as signs of compensation. Naturally the wheelchair handicapped is equally affected by the temptations of modern society. Overnutrition and weaknesses of the autonomic nervous system occur quite frequently. The disabled does not necessarily look for a counter balance against his lack of mobility. He seeks relaxation through further inactivity or simple entertainment. Many disabled confine themselves to their homes since the environment offers too many encumbrances. 
In conclusion one can say, that the paraplegic is endangered by all intrinsic risk factors referred to by Hollmann (I965) as causes for the development and promoting of cardiovascular weaknesses. There are the following factors:

I. A non-physiologically based nutrition (quantity and quality).

2. Abuse of luxuries (tobacco and alcohol).

3. Nervous tension (stress).

4. Lack of exercise.

A general cardiovascular weakness must have a more substained effect on the more endangered paraplegic. Additionally, the health of the paraplegic is endangered due to the insufficiency of his urogenital system (Breithaupt, I96I). The trend to infections and formations of stones in the urinary tract can be diminished by a good cardiovascular function and sufficient exercise (Paeslack, 1965). The paraplegic engaged in regular occupation is still more subjected to the dangers of industrialisation than the non-disabled. If sports activity is necessary for the nondisabled, how much more must it be for the wheelchair-bound!

II. The Adaptation Processes and Basic Principles of Exertion for the Different Forms of Exercise. Nowadays sports medicine can make criteria according to which the value of the adaptive processes for the various sports to health can be estimated. It is known, that the rather common belief that 'participation in sports is healthy' cannot stand as a whole. This is only true, if one has more precise knowledge of the extent, intensity, type and frequency of the physical exercise involved. The examination of the effectiveness of certain sports will be meaningful in such cases, where time for exercises and space are limited. Many disabled cannot invest a great deal of the time due to the long distance they have to travel. Special examinations have shown that there are no principal differences in the adaptive processes of the cardiovascular system, the muscular system and the autonomic nervous system, as compared with the non-disabled (Jung et al., 1971). For this reason the close relations obtained from sports medicine and coaching also apply to the paraplegic and, can at least, give a first approach to the problem:

(a) Endurance training is the most suitable form of exercise for the prevention of cardiovascular weakness and seen from the point of health the most valuable. Speed training as well as strength training do not lead to any measurable developments on the inner organs and their functions (Hollmann, 1965). The cardiovascular performance of the weight lifter, for example, hardly varies from that of the non-athlete. Which criteria are then needed in an exercise to improve the endurance level ?

(b) The form of exercise must be of a dynamic nature and carried out for at least 3 minutes with an intensity of 50 per cent. of the maximum, involving $\frac{1}{7}-\frac{1}{6}$ th of the skeletal muscles. For example, during the third decennium of life the pulse rate during exercise should lie in the area of I30-I40 beats per minute (Hollmann, I965). One should not, however, be fooled by the high pulse rates, which occur during isometric strength training.

An increased blood volume, a better vascularisation and an increased cellular metabolism are reasons for the improved oxygen uptake, which cannot be achieved through muscle-strength training. In this case there would soon result a decrease in the $\mathrm{O}_{2}$-uptake-level, since the diffusion 
pathways would be lengthened due to the enlargement of the cross-section of the muscle. If an improvement or at least a retainment of a certain physical performance level should result, the next interest should be the frequency and volume of the training stimuli.

(c) A daily endurance training of approximately 70 per cent. of the maximal aerobic capacity lasting only Io minutes will lead to an increase in performance (Hollmann, I965). A weekly training of the cardiovascular system can retain a present performance level and may eventually improve it (Hollmann, I965).

\section{DISCUSSION}

Endurance training is to be preferred to strength and speed training from a health point of view. The improvement of the general endurance can be achieved through exercises based on the following criteria:

The involvement of more than I4 per cent. of the skeletal muscles, type of exercise: dynamic-cyclic, intensity: 50 per cent., pulse rate I30-I40, length of the exercise: more than 3 minutes.

A daily cardiovascular training may give the untrained a sufficient protection against the present risk factors of life. Cardiovascular training must be carried out at least once a week if a slight improvement is to be achieved.

The qualification of particular sports for maintaining the health of the paraplegic.

Naturally it would be satisfactory, if every wheelchair-disabled would perform a I0-minute endurance daily, with the wheelchair or bali-exerciser. Similarly, the non-disabled rationalised thinking does not work. Motivation is needed, that will appeal at the same time to the ambitions and desires of the disabled. Such needs can be satisfied by participation in sports within a social group. At the same time partaking in sports may fulfil the exercise requirements. These exercises will induce an improvement of the cardiovascular system.

Now, if one examines the different sports on their physical requirements, one will see that only swimming, long-distance wheelchair races, and wheelchair basketball can fulfil the requirements needed for a good cardiovascular training (dynamic exercises, use of many muscle groups, high intensity and long performance time). Pulse rates were measured telemetrically during a basketball game. The pulse rates for the trained subjects rose over the entire 30 minutes of play around I60 beats per minute. The basketball game displays the criteria which Hollmann (1963) defines as especially effective in the sense of a cardiovascular training. The basketball game encompasses endurance requirements with short intervals of power work, especially during stopping and turning. This game is, however, very strenuous. As basketball requires many skills, it is not suited for the beginner or less adapted person. Distance work with the wheelchair as well as swimming with the corresponding intensities are more suited.

Table tennis, weight lifting, fencing, field and track events as well as archery do not have an adequate stimulus in the form of endurance work or cardiovascular training. The increase of the pulse rate and profuse sweating, which can be caused in these disciplines by psychological strain and short high muscle tension, should not decieve us about their limited effectiveness.

The above mentioned sports, other than archery, have a disadvantage, if one 
considers the practising of these sports. Many clubs are happy when they can plan two practice sessions per week and have at least one supervisor. The technical aspects of track and field events, for instance, need more than one aid if practised with a group of Io to I5 participants. In the case of swimming, however, if the pool has the necessary equipment for the disabled and also in the case of basketball, the simultaneous participation of all members can be achieved with a comparatively low expenditure for personnel.

\section{SUMMARY}

Not only the type of exercise requirement, but also the reasonable practical realisation supports the approval of such sports as swimming, basketball and long distance wheelchair racing, if one includes sports as an important tool in rehabilitation. The authors do by no means reject other competitive sports, but under limited conditions one should emphasise sports with a proved preventive effect in the framework of recreational activities.

\section{REFERENCES}

BREITHAUP, D. J. (I96I). Late causes of death and life expectancy in paraplegia. Cand. med. Ass. F. 85.

HeIPERTZ, W. (I956). Die Bedeutung von Sport und Spiel in der Behandlung Querschnittsgelähmter. Sportmedizin, 7, 296-299.

HEIPERTZ, W. (1964). Sportmedizin. Stuttgart: Thieme.

HollmanN, W. (1959). Der Arbeits- und Trainingseinfluss auf Kreislauf und Atmung. Darmstadt: Dietrich Steinkopf.

HollmaNN, W. (1963). Höchst- und Dauerleistungsfähigkeit des Sportlers. München: J. A. Barth.

HollmanN, W. (1965). Körperliches Training als Prävention von Herä-Kreislaufkrankheiten. Stuttgart: Hippokrates.

JUNG, K., GOTTHEINER, V. \& BRUNNER, D. (I97I). Kombinierte spiroergometrische Untersuchungen bei Versehrtensportlern. Zeitschrift fur physikalische Medizin, 125I4I.

PAesLACK, V. (1965). Internistische Störungen beim Paraplegiker. Stuttgart: Thieme. 